\title{
Interferences from blood collection tube components on clinical chemistry assays
}

\author{
Raffick A.R. Bowen*1, Alan T. Remaley² \\ 'Department of Pathology, Stanford University, Stanford, CA 94305, USA \\ 2Department of Laboratory Medicine, National Institutes of Health, Bethesda, MD 20892, USA \\ ${ }^{*}$ Corresponding author: rbowen@stanfordmed.org
}

\begin{abstract}
Improper design or use of blood collection devices can adversely affect the accuracy of laboratory test results. Vascular access devices, such as catheters and needles, exert shear forces during blood flow, which creates a predisposition to cell lysis. Components from blood collection tubes, such as stoppers, lubricants, surfactants, and separator gels, can leach into specimens and/or adsorb analytes from a specimen; special tube additives may also alter analyte stability. Because of these interactions with blood specimens, blood collection devices are a potential source of pre-analytical error in laboratory testing. Accurate laboratory testing requires an understanding of the complex interactions between collection devices and blood specimens. Manufacturers, vendors, and clinical laboratorians must consider the pre-analytical challenges in laboratory testing. Although other authors have described the effects of endogenous substances on clinical assay results, the effects/impact of blood collection tube additives and components have not been well systematically described or explained. This review aims to identify and describe blood collection tube additives and their components and the strategies used to minimize their effects on clinical chemistry assays.
\end{abstract}

Key words: blood collection devices; blood collection sample tube; clinical assays; clinical chemistry; interference; pre-analytical; surfactant

\section{Introduction}

Proper blood collection and timely processing are critical pre-analytical steps required for the integrity of laboratory results. Although the influence of blood collection devices on laboratory tests is often overlooked, correct pre-analytical handling is essential. However, many laboratorians do not carefully evaluate the suitability of new devices or monitor ongoing performance. In this review, we discuss how blood collection materials and devices can alter chemistry test results, with an emphasis on blood collection tube (BCT) additives.

\section{Blood collection device history}

Reusable glass syringes with steel hypodermic needles and a hard rubber hub were the first devices used to collect blood (1). Early modifications included a refined needle, replacement of the rubber hub with glass, and the Luer-Lok syringe, which modified the needle tip for a more secure attachment to the syringe and ensuring a more reliable and safer drug delivery (1). Glass syringes were expensive to manufacture and were susceptible to breakage (2); nevertheless, what ultimately prompted their replacement with sterile disposable syringes (1) were the multiple hepatitis outbreaks that resulted from their use (1). Modern chemical sterilization techniques and radiation allowed the replacement of glass syringes by plastic syringes.

Since the 1940s, evacuated BCTs have been the most commonly used blood collection devices, since they automatically draw a predetermined blood volume and switching between tubes for additional samples poses a lower risk of spillage and needle-stick injury (3). Thus, the evolution of blood collection tubes have improved specimen 
quality and workflow efficiency as well as the safety of patients and health care workers.

Glass evacuated tubes containing anticoagulants were commonly used from the 1950 s to the 1990 s (4). Presently, plastic has replaced glass, and polymer gels and clot activators are common additives (5). Despite their similarity, evacuated tubes supplied by different manufacturers vary in the materials and additives used, which can potentially affect test performance (6). In the United States, there are two major manufacturers of evacuated tubes: Becton Dickinson (BD) (Franklin Lakes, NJ, USA) and Greiner Bio-One (Monroe, NC, USA).

Because BCTs function properly under most circumstances, many laboratorians are unaware of their complexity and limitations. A widespread surfactant (SF) problem revealed how these devices can adversely affect laboratory test results $(7,8)$ and emphasized the importance of understanding device limitations.

\section{Blood collection tubes}

BCTs consist of tube walls, rubber stoppers, lubricants, anticoagulants, separator gels, clot activators, and SFs, all of which can affect the quality of the specimens, accuracy and precision of laboratory tests (Figure 1).

\section{Tube walls}

Evacuated BCTs are generally cylindrical, measuring $50 \mathrm{~mm}$ to $150 \mathrm{~mm}$ in length and $10 \mathrm{~mm}$ to 20 $\mathrm{mm}$ in diameter (9). Most tubes for adult clinical specimens are $75 \mathrm{~mm}$ to $100 \mathrm{~mm}$ in length and 13 $\mathrm{mm}$ in diameter, and collect 2 to $10 \mathrm{~mL}$ of whole blood $(9,10)$. Micro-collection tubes for pediatric specimens are 40 to $50 \mathrm{~mm}$ in length and 5 to 10 $\mathrm{mm}$ in diameter (11). Evacuated tubes were originally made from soda-lime or borosilicate glass, but soda-lime tubes were found to release calcium and magnesium into blood specimens (12). Glass evacuated tubes are manufactured to be airtight, waterproof, and thermally resistant, which allows for vacuum preservation and long shelf lives (13). The contact of blood coagulation factors, such as Factor XII (Hagemann Factor), with hydrophilic glass surfaces activates the clotting cascade lead-

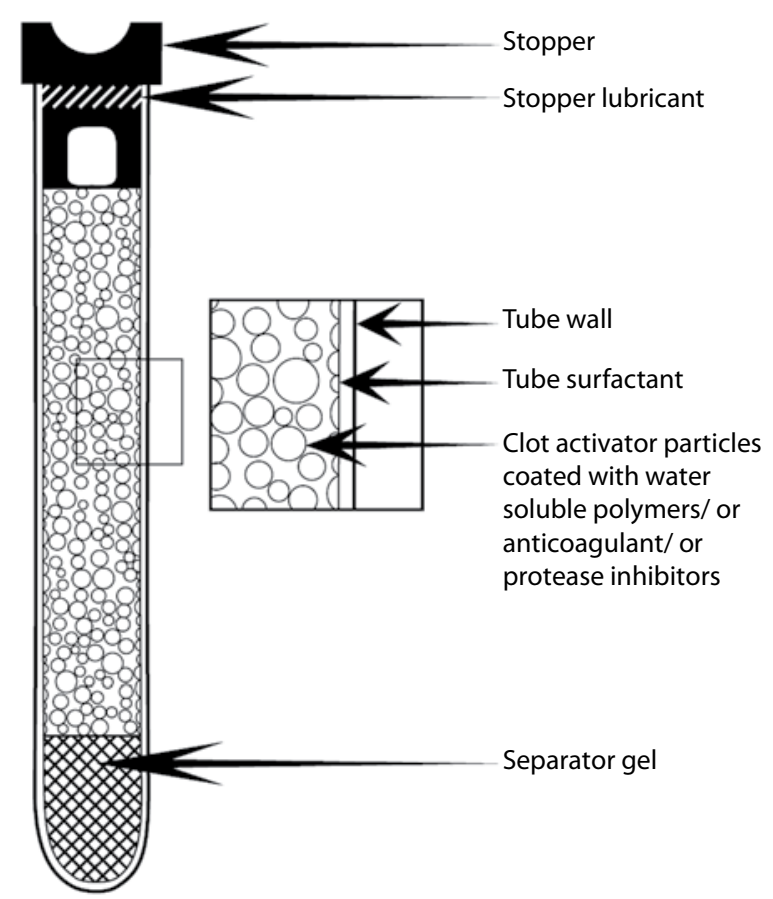

Figure 1. Components of an evacuated blood collection tube. Reprinted from Clinical Biochemistry, 43 (1-2), Bowen RAR, Hortin GL, Csako G, Otanez O, Remaley AT. Impact of blood collection devices on clinical chemistry assays, pages 4-25, 2010, with permission from Elsevier.

ing to the conversion of fibrinogen to fibrin, thus enabling the separation of the non-adherent clot from blood plasma by centrifugation (14). However, clot re-suspension into plasma during handling or transport can interfere with assays attributable to the effects of hemolysis on test results $(15,16)$.

Plastic tubes recently replaced most glass tubes following the establishment of the Occupational Safety and Health Administration (OSHA) guidelines to improve safety and reduce exposure to blood-borne pathogens (15). Plastic tubes are manufactured through injection-molding, using polyesters (e.g. polyethylene terephthalate (PET)), polyolefins (e.g. polyethylene and polypropylene (PP)), polyacrylic, polytetrafluoroethylene, polysiloxane, polyvinyl chloride, polyacrylonnitrile, and polystyrene $(9,10)$. Compared to glass, plastic minimizes exposure to biohazardous material following breakage, has a greater shock resistance, tolerates higher centrifugation speeds, weighs less, has excellent dimensional precision, and is more easily disposed of by incineration at a lower cost $(4,17)$. 
However, plastic has greater gas permeability compared to glass tubes (18). There have been numerous studies comparing glass and plastic tubes for use in chemistry $(4,19)$, endocrinology (19), molecular testing (20), serology (21), and coagulation testing $(10,19)$. Despite small statistically significant differences between plastic and glass tube analyte determinations, none is considered clinically significant. PET, a commonly used plastic in the manufacture of BCTs is unbreakable and maintains a vacuum for a prolonged time (22). PP, another commonly used plastic, has a lower water permeability, allowing it to retain liquid anticoagulant volume and concentration (22). Thus, PET tubes have double-walls to minimize evaporation, especially for coagulation-based tests (22); the internal PP layer protects against citrate solution evaporation, whereas the outer PET layer is more transparent, allowing easier visualization of tube fill levels. The PP plus PET combination improves shelf life and anticoagulant volume retention (22).

Plastic tubes generally have a hydrophobic surface and do not efficiently activate the coagulation process (23); clots formed on the plastic surfaces of tubes are gelatinous compared to clots formed in glass tubes (23). Further, blood does not flow smoothly over hydrophobic plastic surfaces, which can result in the adherence of platelets, fibrin, or clotted blood on the tube walls (23). This can make it difficult to cleanly separate serum from the blood clot by centrifugation, especially for microcollection tubes or during centrifugation of vacuum tubes. The hydrophilicity of plastic surfaces can be increased by using plasma-enhanced chemical vapor deposition to introduce polar functional groups (24). Alternatively, the interior plastic surfaces can be coated with SFs, water-soluble polymers, or hydrophilic-hydrophobic copolymers (23), although SFs may dissolve in blood and interfere with clinical tests (8). There are ongoing efforts to incorporate SFs into plastic tubes to prevent exudation into blood specimens $(9,10)$.

\section{Rubber stoppers}

Rubber stoppers are routinely color-coded according to anticoagulant type and the presence of a separator gel. The stopper should be readily pen- etrated by a needle and self-seal upon needle removal (23), maintaining the internal pressure differential (23). Suitable materials include polychloroprene, silicone, styrene butadiene, isobutyleneisopropene, chlorinated ethylene-propylene copolymers, and isobutylene-isoprene rubber $(23,25,26)$. Butyl rubber, a copolymer of isobutylene and isoprene, and halogenated butyl rubber are commonly used materials $(23,25,26)$; butyl rubber exhibits superior air and moisture impermeability, superior resistance to chemical attack and heat resistance, and good processability $(25,26)$. To reduce the potential for splatter from the blood specimen when the rubber stoppers are removed from the collection tube, a stopper shield is used (e.g. Hemogard $\left.{ }^{\mathrm{TM}}\right)$. The stopper shield can be made from thermoplastic materials, such as polyethylene, polypropylene, and polyvinylchloride $(8,26)$. Discrepancies in the bioavailability and bioequivalence of tests for blood specimens collected into tubes whose rubber stoppers containing the plasticizer tris-(2-butoxyethyl)-phosphate (TBEP) have been reported (27). TBEP, which is used to make stoppers soft, displaces certain drugs from plasma-protein binding sites, such as the $a_{1}$-acid glycoprotein (28), resulting in increased drug uptake by red blood cells (RBCs), thus artificially lowering serum or plasma levels. TBEP has been reported to alter the drug distribution of quinidine, propranolol, lidocaine, tricyclic antidepressants, and several phenothiazine drugs, including fluphenazine and chlorpromazine (29). Therefore, tube manufacturers have decreased or eliminated production of rubber stoppers containing TBEP (27). Janknegt et al. (30) have demonstrated that rubber stoppers made without TBEP do not interfere with therapeutic drug monitoring. However, other stopper components can also pose problems. Curry et al. (31) reviewed how materials from elastomeric closures, including butyl rubber stoppers, can contaminate specimens with these container closures. Metals such as calcium, aluminum, magnesium, and zinc are used to manufacture rubber stoppers; it is essential that these metals are not extracted upon contact with blood (32); specially formulated rubber stoppers have been made to limit divalent cation leaching (33). Sulfur, sulfur-containing vulcanization accelerators, fatty acids, and peroxides 
in stoppers can also potentially affect lab tests; therefore, most stoppers are manufactured with low-extractable rubber or have been modified to minimize leaching into the blood specimens (29). The complete filling of BCTs dilutes any leached material and helps reduce the effects (34). Further, specimens in tubes with rubber stoppers should be stored at low temperatures $\left(2{ }^{\circ} \mathrm{C}\right.$ to $\left.8^{\circ} \mathrm{C}\right)$ and in the upright position to minimize leaching (34).

\section{Stopper lubricants}

Lubricants, such as silicone oils, fluids, and glycerol, facilitate the insertion and removal of stoppers $(6,9,10)$. Lubricants minimize red blood cell and clot adherence to stoppers in order to prevent serum or plasma contamination $(6,9,10)$. However, glycerol should not be used to lubricate stoppers used for specimens measuring glycerol or triglyceride when a non-glycerol blank assay is used (35). Siliconized stoppers are generally preferred because they are less likely to interfere with assays, although silicone may falsely elevate ionized magnesium and total triiodothyronine levels (7) and may confound peaks during mass spectrometry (MS) analysis and peak interpretation (36).

\section{Anticoagulants}

Although serum is used for most assays, plasma is a useful alternative due to its rapid processing time. Plasma, which contains fibrinogen and other clotting factors, has a higher viscosity and total protein content than serum (37). Serum has a higher concentration of thromboglobulins, potassium, activation peptides for coagulation factors, platelet factor 4, and platelet components released during platelet activation (37). Anticoagulants used to preserve analytes may interfere with other analyte determinations when using plasma (38). Ethylenediaminetetraacetic acid (EDTA), heparin, and citrate are the most commonly used anticoagulants (39-41).

Potassium EDTA (Table 1), an anticoagulant and chelating agent, interferes with calcium assays and clot generation (42), but it is preferred for hematology testing. EDTA binds the metallic ions europium (immunoassay reagent), zinc, and magnesium (enzyme cofactors for immunoassay reagents such as alkaline phosphatase) (43). Insufficient sample volumes produce relatively elevated EDTA levels, which can increase the chelation of magnesium and zinc, and can then affect reagent enzymes used for signal generation, such as alkaline phosphatase (43). Reagent antibodies recognize divalent cation complex binding sites on proteins; thus, decreased calcium and magnesium levels may induce conformational changes that decrease antibody binding (43).

Heparin salts (typically from porcine intestinal mucosa) are also extensively used as anticoagulants in BCTs (Table 1) (44). Heparin complexes with and induces a conformational change of antithrombin III to accelerate the inhibition of thrombin and Factor Xa (35), which prevents thrombin activation and the generation of fibrin from fibrinogen. Since heparin binds electrolytes and changes the concentration of bound and free ions (45), manufacturers have created electrolyte-balanced formulations (45). However, heparin can interfere with a variety of clinical assays. Specimens assayed with Dimension $^{\text {TM }}$ Vista 1500 (Siemens Healthcare Diagnostic, Newark, DE, USA) may produce negative anion gaps due to heparin interference with chloride electrode membranes (unpublished observation). Heparin also slows some antibody-antigen reaction rates (46), particularly during the precipitation step in second-antibody systems, although this problem can be avoided with the use of solidphase systems (47). Heparin should also be avoided in cryoprotein investigations since it precipitates cryofibrinogen $(43,47)$. Exogenously administered heparin alters serum thyroid hormone levels $(43,47)$. Falsely low albumin levels have been observed when heparinized tubes have been used on hemodialysis patients (48). It is has been proposed that heparin inhibits the binding of bromocresol green to albumin, leading to less colorimetric complex formation (48). Proteomic studies show that heparinized plasma causes non-specific protein binding, which influences the separation and MS of peptides (49). Recently, Lippi et al. (50) demonstrated that incomplete filling of lithium heparin tubes produced significantly higher creatine kinase and $\gamma$-glutamyltransferase activity on a Unicel DxC 800 analyzer. 
TABLE 1. Evacuated blood collection tube stopper color and additives.

\begin{tabular}{|c|c|c|}
\hline $\begin{array}{c}\text { Stoper color* } \\
\text { (tube wall material) }\end{array}$ & Additive(s) & $\begin{array}{l}\text { Amount/ } \\
\text { concentration }\end{array}$ \\
\hline Red (glass) & $\begin{array}{c}\text { Clot activator } \\
\text { Uncoated interior }\end{array}$ & \\
\hline Gold (plastic) & Clot activator with separator gel & \\
\hline Red/black (plastic) & Clot activator with separator gel & \\
\hline Red/gray (plastic) & Clot activator with separator gel & \\
\hline Orange (plastic) & Thrombin with separator gel & $\begin{array}{l}\text { 10-15 National Institute of Health } \\
\text { units per tube (10) }\end{array}$ \\
\hline Light blue (plastic) & $\begin{array}{l}\text { Citrate, trisodium (liquid additive) } \\
\text { (1 part additive to } 9 \text { parts of blood) }\end{array}$ & $0.109 \mathrm{M}(3.2 \%)$ or $0.129 \mathrm{M}(3.8 \%)$ \\
\hline Dark green (plastic) & Heparin, sodium (dry additive) & 10-30 USP units $/ \mathrm{mL}$ blood \\
\hline Light green (plastic) & Heparin, lithium (dry additive) with separator gel & 10-30 USP units $/ \mathrm{mL}$ blood \\
\hline Green/gray & Heparin, lithium (dry additive) with separator gel & 10-30 USP units $/ \mathrm{mL}$ blood \\
\hline Lavender (plastic) & EDTA, dipotassium (dry additive) & $1.5-2.2 \mathrm{~g} / \mathrm{L}$ blood \\
\hline Lavender (plastic) & EDTA, tripotassium (liquid additive) & $1.5-2.2 \mathrm{~g} / \mathrm{L}$ blood \\
\hline Lavender (plastic) & EDTA, disodium (dry additive) & $1.4-2.0 \mathrm{~g} / \mathrm{L}$ blood \\
\hline Gray (plastic) & Sodium fluoride/potassium Oxalate (dry additive) & $\begin{array}{c}\text { Sodium fluoride: } 2.5 \mathrm{~g} / \mathrm{L} \text { blood; potassium } \\
\text { oxalate: } 2.0 \mathrm{~g} / \mathrm{L} \text { blood }\end{array}$ \\
\hline Gray (plastic) & Sodium fluoride/sodium EDTA (dry additive) & $\begin{array}{l}\text { Sodium fluoride: } 2.5 \mathrm{~g} / \mathrm{L} \text { blood; sodium } \\
\text { EDTA: } 1.5 \mathrm{~g} / \mathrm{L} \text { blood }\end{array}$ \\
\hline Gray (plastic) & Lithium iodoacetate & lodoacetate: $\sim 2 \mathrm{~g} / \mathrm{L}$ blood \\
\hline Yellow (glass) & $\begin{array}{l}\text { Acid Citrate Dextrose }(A C D) \text { - solution } A \\
(1 \text { part additive to } 5.67 \text { parts of blood })\end{array}$ & $\begin{array}{c}\text { Citrate, disodium, } 22.0 \mathrm{~g} / \mathrm{L} ; \text { citric acid, } 8.0 \\
\mathrm{~g} / \mathrm{L} ; \text { dextrose, } 24.5 \mathrm{~g} / \mathrm{L}\end{array}$ \\
\hline Yellow (glass) & $\begin{array}{l}\text { Acid Citrate Dextrose }(A C D) \text { - solution } B \\
(1 \text { part additive to } 3 \text { parts of blood })\end{array}$ & $\begin{array}{c}\text { Citrate, disodium, } 13.2 \mathrm{~g} / \mathrm{L} ; \text { citric acid, } 4.8 \\
\mathrm{~g} / \mathrm{L} ; \text { dextrose, } 14.7 \mathrm{~g} / \mathrm{L}\end{array}$ \\
\hline
\end{tabular}

Royal blue (glass) (with red band on label)

None

Royal blue (glass) (with lavender band on label)

EDTA, dipotassium (dry additive)

$\sim 1.8 \mathrm{~g} / \mathrm{L}$ blood

\begin{tabular}{ccc}
\hline Tan (plastic) & EDTA, dipotassium (dry additive) & $1.8 \mathrm{~g} / \mathrm{L}$ blood \\
\hline Black (glass) & Sodium citrate & $0.105 \mathrm{M}(\sim 3.2 \%)$ \\
\hline Clear (plastic) & None & \\
\hline Red/LightGray (plastic) & None & \\
\hline
\end{tabular}

*Single or multiple stopper color combinations may vary from different tube manufacturers.

Table modified from the Clinical and Laboratory Standards Institute: Evacuated Tubes and Additives for Blood Specimen Collection; Approved standard H3-A4 (40) and information from Young et al. (41) and in the BD website (42). Reprinted from Clinical Biochemistry, 31 (1-2), Bowen RAR, Hortin GL, Csako G, Otanez O, Remaley AT. Impact of blood collection devices on clinical chemistry assays, pages 4-25, 2010, with permission from Elsevier.

Trisodium citrate in a $3.2 \%(109 \mathrm{mmol} / \mathrm{L})$ or $3.8 \%$ $(129 \mathrm{mmol} / \mathrm{L})$ solution is preferred for coagulation testing (Table 1) (51). It can inhibit both aspartate aminotransferase and alkaline phosphatase by the chelation of cations (51). Sodium citrate, which is used in acid citrate dextrose and citrate theophylline adenosine dipyrridamole (51), inhibits platelet activation and is used to measure plasma levels of platelet-derived components. 
Potassium oxalate, another calcium-chelating anticoagulant (Table 1) often combined with antiglycolyitc agents (sodium fluoride and sodium iodoacetate) can actually decrease hematocrits by as much as $10 \%$ by drawing water from cells into plasma (51). Oxalate can also inhibit several enzymes, such an amylase, lactate dehydrogenase, and acid and alkaline phosphatase (51).

Sodium fluoride (Table 1) inhibits the glycolytic enzyme enolase and is used to limit the ex vivo consumption of glucose by cells in a collected blood specimen (51). However, in fluoridated, non-separated blood samples, glucose is still metabolized at approximately 5\% to $7 \%$ per hour at room temperature because upstream enzymes continue to convert it to glucose-6-phosphate (52). Hence, complete inhibition of glycolysis in fluoride-containing tubes can take up to 4 hours at room temperature with a normal blood cell count (53). Fluoridated tubes can affect diabetes diagnosis, which uses fixed plasma glucose levels established using blood that was iced, centrifuged, and had the plasma removed (54). In fact, the American Diabetes Association no longer recommends using sodium fluoride only to inhibit in vitro glycolysis (54). A BCT with EDTA and fluoride in a citrate buffer $(\mathrm{pH}<5.9)$ has been proposed to preserve glucose concentrations due to its immediate inhibition of glycolysis (53). Sodium fluoride may be unsuitable for enzymatic immunoassays because of its enzyme inhibitory activity (51). Fluoride may also interfere with electrolyte measurements by altering cell membrane permeability (51) and promoting hemolysis by red blood cell ATP with subsequent potassium efflux (51). lodoacetate preserves glucose concentrations by inhibiting glyceraldehyde3-phosphosphate dehydrogenase, but it can interfere with the measurement of glucose, sodium, potassium, chloride, and lactate dehydrogenase measurements and can cause hemolysis (51).

Although anticoagulants and antiglycolytics can be unsuitable for certain assays, assay manufacturers do not always specify the plasma sources used to validate their tests. Consequently, it is important that clinical laboratories assess tube performance with their particular assays, instruments, and platforms. Tube manufacturers' fill-volume recom- mendations should be followed to ensure proper additive to blood ratios and minimize assay interference and resultant laboratory errors, repeat testing, and unnecessary troubleshooting.

\section{Separator gels}

Separator gels are used to separate serum from clotted whole blood or plasma from cells (55). In this regard, serum separator tubes (SST) are easy to use, require short processing times, yield higher serum levels, limit hazardous aerosolization, require only one centrifugation step, allow primary tube sampling, and require a single label (55).

During centrifugation, the thixotropic gel used in these tubes lodges between packed cells and the top serum layer (56). The position of the gel after centrifugation is influenced by many tube characteristics, such as specific gravity, yield stress, viscosity, density, and tube material. It can also be affected by temperature, centrifugation speed, acceleration and deceleration, storage, and patient factors, such as heparin therapy, low hematocrit, elevated plasma protein, and serum/plasma specific gravity (57). Polymeric gels affect viscosity, density, and other physical properties. Separator gels are typically made from viscous liquids, fillers, or tackifiers with substances like dibenzylidene sorbitol as a gelling agent (23). The inner tube surface may have a hydrophobic coating to ensure separator gel adherence and a complete barrier to prevent mixing between RBCs and serum/plasma $(9,10)$. Because the serum/plasma specific gravity ranges from 1.026 to $1.031 \mathrm{~g} / \mathrm{cm}^{3}$, and the clot specific gravity ranges from 1.092 to $1.095 \mathrm{~g} / \mathrm{cm}^{3}$, the separator gel specific gravity should ideally be within 1.03 to $1.09 \mathrm{~g} / \mathrm{cm}^{3}$ (58). If the serum/plasma specific gravity is elevated due to hyperproteinemia or radio-contrast dye, the serum may not float above the gel (57). Fatas et al. (58) showed that the specific gravity is a more important factor than viscosity affecting improper BCT gel separation. In addition, Faught et al. (59) showed differences in separator gel specific gravity in different BCTs and between some tube lots.

Several reports of gels affecting analyte concentrations have been published. Hydrophobic drugs, such as phenytoin, phenobarbitol, carbamazepine, 
quinidine, and lidocaine, can adsorb onto hydrophobic separator gels and lead to a decrease in serum drug concentrations by as much as $20 \%$ to $50 \%$ after 24 hours at $4{ }^{\circ} \mathrm{C}(60,61)$. Organochlorine, polychlorinated biphenyl, and progesterone levels may also be significantly reduced (47). A small but statistically significant difference in myoglobin and CK-MB levels has been reported between tubes with and without separator gels (5). Interestingly, newer separator gels (e.g. polydimethylsiloxanepolyethylene oxide copolymers) that minimize drug and analyte adsorption have been developed (e.g., the BD SST II ${ }^{\mathrm{TM}}$ tube) $(9,10,62)$. Recently, RBCs have been observed to surpass the separator gel barrier in plasma and serum tubes increasing the plasma/serum potassium levels (63). Separator gels may also release materials (e.g., gel pieces and silicone oil) into the specimens and spuriously interfere with assays, sample probes, tubes and cuvettes, solid-phase immunoassay systems, and electrode surfaces $(47,64)$; the rate of degradation and release may be increased by improper storage or extreme temperatures (47). Recently, Shi et al. (65) demonstrated that the separator gel components in some types of BCTs (i.e., SST and lithium heparin plasma separator tubes) from a specific tube manufacturer were the source of interference in the quantitation of serum testosterone levels using liquid chromatography-tandem MS. The interference increased according to the length of storage of serum in the tubes and was more pronounced with specimens containing low testosterone levels (65). Modifications of the assay and liquid chromatography-tandem MS parameters did not resolve the tube interference problem with the quantitation of serum testosterone levels (65). Thus, new technologies applied in the clinical laboratory to determine analyte concentrations can be significantly affected by BCTs components such as the separator gel. Ideally, separator gels should maintain uniform chemical and physical properties for the intended period of use and be inert to the specimens collected in BCTs.

\section{Clot activators and water-soluble agents}

Plastic tubes require clot activators that use either intrinsic or extrinsic pathways to ensure rapid and dense clot formation (10). Clot activation by the in- trinsic pathway is surface-dependent and a greater density of activating surface sites speeds clotting time. Siliceous substances (e.g., glass, silica, kaolin, bentonite, diatomaceous earth) accelerate clot formation through contact activation (23), but particulate clot activators work relatively slowly (30 to 60 minutes) (10). The amount of clot activator varies by manufacturer (23). Clot activators also diminish latent fibrin formation in the separated serum (47). Clot activation by the extrinsic pathway, coagulation initiated by adding substances extrinsic to blood, is biochemical (e.g., ellagic acid, thrombin, snake venoms, thromboplastin) and concentration-dependent (10). Although these clot activators produce rapid clotting (10 to 20 minutes), the clots formed are gelatinous and do not easily separate from serum (10). Clot activators can be added to tubes by adding small beads or paper coated discs, or they can be sprayed on interior tube surfaces with a carrier (e.g., polyvinylpyrrolidone (PVP), carboxymethyl cellulose, polyvinyl alcohol, and polyethylene oxide) $(10,23)$. These carriers allow rapid clot activator suspension into blood so that the carriers dissolve into both serum and clots as the clotting is initiated (23). PVP and water-soluble SFs also release clot activators into blood specimens to reduce the need for mixing (23). BD has recently released a serum tube containing thrombin (rapid serum tubes (RST ${ }^{\mathrm{TM}}$ ); Table 1, orange stopper) for rapid clot activation (within 5 minutes) (42). Dimeski et al. (66) demonstrated that the use of RST tubes would not be appropriate for patients on high-dose heparin or warfarin therapy since latent clot formation in the tube may clog instrument probes and produce erroneous test results. Based on these findings, it is clear that additional studies are needed to ensure that the RST tubes give clinically equivalent results to other commercially available serum tubes, especially for partially filled tubes of blood.

Some clot activators are problematic in that they must be thoroughly mixed to allow complete pelleting with the clot. If soluble fibrin clots form, they can interfere with pipetting device accuracy or in solid-phase binding in immunoassays (67). To limit these problems, plasma gas may be used to introduce heteroatoms (non-carbon and hydrogen at- 
oms in the backbone of the molecular structure) to the tube wall surface to accelerate clotting without contaminating the serum or clot with binders or activators (24).

Various studies have revealed the impact of clot activators on laboratory test performance. Sampson et al. (68) showed that silica and silicone SF are associated with elevated lithium concentrations when using the Lytening $2 Z$ (Lytening West Peabody, MA, USA) ion-specific electrode analyzer. The clot activators or silicone SFs can interact with ion-specific analyzer membranes, which increase the measured voltage and falsely elevate serum lithium ion concentration. Clot activators can also falsely elevate serum testosterone measurements (69), but changing the ion pair eliminates this problem (69). Proteome analysis by MS may also be altered by clot activators (70). Silica and silicate clot activators, when sprayed onto plastic tubes, induces the release of pro-, active, and complexed matrix metalloproteinases (71). Recently, it was shown that ficolin-1 and ficolin-2 levels, a group of proteins that can activate the complement pathway, and their binding capacities were significantly affected, presumably, by the silicate material in SST tubes (72). Thus, it is critical that the optimal amounts and composition of clot activators and water-soluble agents be determined and consistently added to different types and sizes of BCTs in order for these substances to function properly without adversely affecting the quality of the blood specimens and test results.

\section{Surfactants}

SFs are commonly used to decrease non-specific adsorption, but they must be carefully selected and optimized for immunoassays since, at high concentrations, they may cause the loss of antibodies passively adsorbed onto the solid support beads used in immunoassays (73). Commercially available tubes contain a variety of SFs $(7,8,10)$ that improve blood flow, distribute clot activator, and prevent proteins, RBCs, and platelets from adsorbing to tube walls (10).

Silicone SF-coated tubes have been shown to interfere with ion-specific electrode measurement of ionized magnesium and lithium $(7,68)$. Silicone
SFs seems to interact with ion-specific electrode membranes to increase the measured voltage during magnesium and lithium determinations $(7,68)$. In addition, water-soluble silicone polymer coatings in separator tubes can physically mask antibodies and alter avidin-biotin binding reactions in immunoradiometric assays (74).

Bowen et al. (7) demonstrated that the nonionic polydimethylsiloxane-polyethylene oxide and polypropylene oxide graft copolymer SF, Silwet ${ }^{\mathrm{TM}}$ L-720 (Figure 2; OSI Specialities, Danbury, CT, USA; 75), in BD SST ${ }^{\mathrm{TM}}$ tubes falsely elevates triiodothyronine in a dose-dependent manner by causing the desorption of captured antibodies from the solid phase used in immunoassays $(7,8)$. Competitive immunoassays (e.g., vitamin $\mathrm{B}_{12}$ ) and non-competitive immunoassays (e.g., cancer antigen 15-3) are also affected by Silwet L-720, but the mechanism is unclear (7).

A

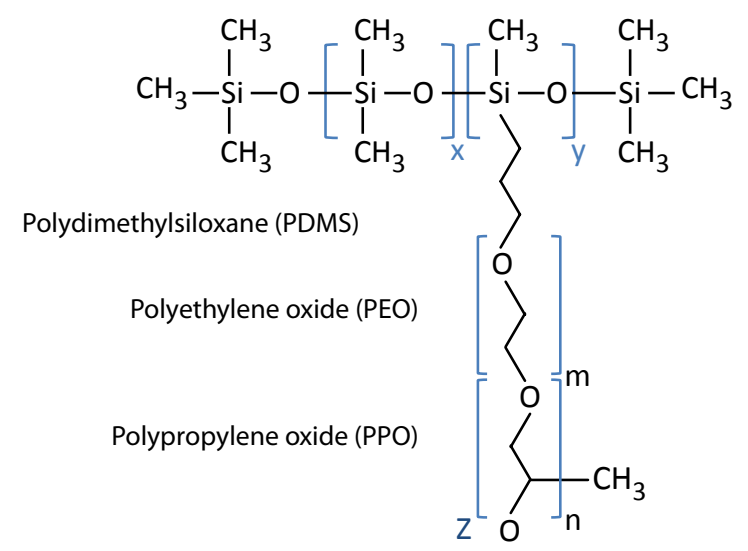

B

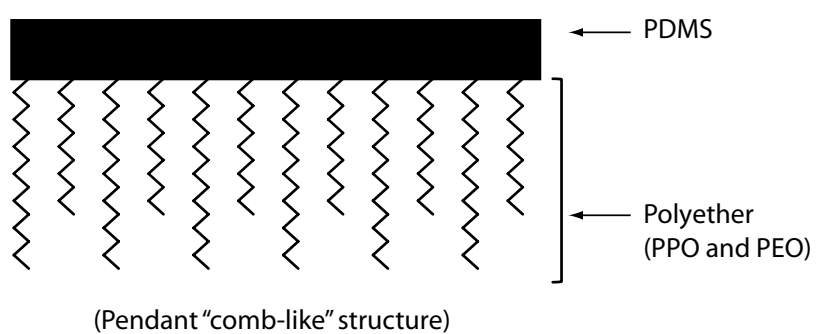

Figure 2. Silwet ${ }^{\text {TM }}$ silicone surfactant. A) general molecular structure and B) schematic structure with polyether (polyethylene oxide and polypropylene oxide) attached (via hydrosilation reaction) to the polydimethylsiloxane backbone; $x, y, m, n$ are integers independently greater than zero; $z$ can be hydrogen or alkyl radical (75). 
Due to immunoassay interference, BD reformulated their tubes to reduce SF levels (7). Morovat et al. (76) have shown statistically significant but clinically insignificant biases in immunoassay results using these reformulated tubes. Yet, in this study, the control tubes were coated with the problematic SF. Wang et al. (77) reported that the reformulated tubes produced clinically significant biased results for free triiodothyronine and free thyroxine. Interestingly, Silwet L-720 and other types of Silwet surfactants can be used in separator gel formulations, which may account for the clinically significant biased thyroid hormone test results with the reformulated tubes stated above (75).

Further studies have examined whether additives supply molecules that may interfere with MS peaks. Drake et al. (36) showed that seven of the eleven tubes tested contained various components, such as SF and polyvinylpyrrolidone, which produced multiple MS signals in the $\mathrm{m} / \mathrm{z}$ range of 1,000 to 3,000 . These tube additive peaks complicate and compromise mass spectra interpretation in the low molecular mass range, particularly for MALDI or SELDI techniques (36). Tube additives may also affect the ionization process during liquid chromatography-MS analysis, thereby suppressing metabolite ionization. Yin et al. (78) recently reported that five different S-Monovettes ${ }^{\mathrm{TM}}$ (Sarstedt Newton, NC, USA) BCT additives produced chemical noise in the mass spectra that interfered with metabolic profiling. Thus, an initial step in MS investigations should be the examination of BCTs.

SF detergent properties can also alter cell membrane permeability and lipophilic structures. A study showed that SFs in tubes affected free fatty acid concentrations in specimens rather than interfere with their analytical detection (79). Thus, producing BCTs with SF that do not contaminate the blood specimens and cause assay interferences would be ideal.

\section{Order of draw}

The importance of the order of draw in obtaining accurate laboratory tests has been known for many decades. Calam and Cooper (80) demon- strated that the initial drawing of blood into potassium-EDTA tubes falsely decreased and increased the calcium and potassium values, respectively, in blood collected into subsequent tubes containing no anticoagulants (80). These findings prompted the development of Clinical and Laboratory Standards Institute (CLSI) guidelines to standardize tube sequence and syringe use for blood collection to minimize carryover of tube additives (81). When laboratories switched from glass to plastic tubes, the CLSI order of draw guideline changed because plastic serum tubes were considered equivalent to gel separator tubes with clot activators (81). The current CLSI guideline for glass and plastic tubes order of draw is as follows: blood culture tubes; sodium citrate tubes; serum tubes with and without clot activator and with or without gel separator; heparin tubes with or without gel separator; EDTA tubes; acid citrate dextrose containing tubes; and glycolytic inhibitor (fluoride, iodoacetate) tubes (81). However, the use of order of draw has recently been questioned and studies by Salvagno et al. (82) have demonstrated negligible effects of the order of draw on sample quality for some routine chemistry tests. Nevertheless, an extensive study with more analytes is warranted. Tube manufacturers color-code tube closures for easy identification of tube additives. Laboratorians must understand associated additives, proper order of draw, and carryover effects of additives on clinical assays.

\section{Protease inhibitors}

Protease inhibitors are among the most abundant plasma protein components (83), far outnumbering active proteases except where activation occurs by surfaces or other stimuli. Chelating agents, such as EDTA and citrate, do not directly inhibit serine proteases, but they do limit the activation of proteases in the coagulation system by interfering with calcium-mediated surface binding and by allowing inhibitors to dominate. Direct inhibitors of thrombin or coagulation factor $X$ a serve as alternative anticoagulants, but they have not achieved widespread use because of cost (84). Such products, however, can increase protein stability and allow chemistry and hematology tests 
on a single specimen. Small bioactive peptides such as parathyroid hormone and insulin are more stable in EDTA-anticoagulated plasma compared to citrate-anticoagulated plasma or serum (85). Aprotinin increases the stability of brain-type natriuretic peptides (86); some reference laboratories recommend the collection of specimens for bioactive peptide analysis in tubes containing aprotinin or other protease inhibitors. Many peptides, such as glucagon-like peptide 1, undergo rapid cleavage by the exopeptidase dipeptidyl peptidase IV (87), and thus collection tubes must contain exopeptidase inhibitors to recover the intact peptide. EDTA-containing tubes are generally recommended for proteomic analyses to minimize protein component changes (88); small peptide components can also undergo rapid degradation by exopeptidases (89). However, addition of chemically reactive protease inhibitors, such as sulfonyl halides, can covalently modify proteins (89). An alternative approach is to inhibit protease activity by decreasing $\mathrm{pH}$ (89). In general, small peptides are frequently less stable than proteins since proteases sequestered in an $a_{2}$-macroglobulin inhibitor retain peptidolytic activity even though they are sterically hindered from cleaving full-size proteins (90); further, peptides lack a globular structure and are more accessible to exopeptidase action. Although endogenous protease inhibitors are quite abundant in plasma, most are mainly against serine dependent endoproteases and exhibit relatively little activity against exopeptidases. Therefore, the addition of exogenous, low molecular weight protein inhibitors or small synthetic compounds to a blood specimen is often used to stabilize samples.

Protease activity may be accentuated by the release of intracellular proteases from white or RBCs. For example, insulin is substantially less stable in hemolyzed blood because of the thiol proteases from RBCs (91). The use of protease inhibitors has a limited effect on the recovery of chemokines and cytokines from plasma, but the rapid processing of blood can limit this problem because most cytokines and chemokines are degraded by intracellular protease (92).
The addition of exogenous protease inhibitors depends on the intended use of specimens. Because there is wide variability in protein and peptide stability, each laboratory should analyze the stability of components of interest; where protein or peptide stability problems are identified, protease inhibitors should be considered. Blood collection systems (e.g., BD P100 ${ }^{\mathrm{TM}}$ ) containing a cocktail of protease inhibitors that enable preservation of plasma proteins for proteomic investigation have been developed (42).

\section{Recommendations}

Prevention of pre-analytical errors from BCT additives remains an ongoing problem for tube and assay manufacturers and ultimately affects the ability of clinical laboratories to produce accurate results. Any new or modified blood collection product should ideally be thoroughly evaluated for any potential problems inherently caused in the downstream processing and analysis of specimens. BCT manufacturers should also consider evaluating their products under conditions of reduced specimen volumes, extended contact times, and longterm storage. Because it is not possible for manufacturers to assess the impact of their tubes on all assay platforms, it is important that they establish close working relationships with their customers and should consider developing a surveillance program to quickly identify problems. Similarly, manufacturers of assays and instrument platforms should ideally verify the performance of their assays with a wide variety of BCTs on the market and on different lots of the same tube type. Reference interval studies performed on older instruments or tubes no longer in use should be repeated using materials and conditions that are consistent with current use.

Blood collection device problems may go unnoticed by laboratorians since routine quality control (QC) practice typically does not assess all aspects of laboratory testing from blood collection, including specimen processing, analytical testing, and test reporting $(7,8)$. Proficiency testing programs, which do not require blood collection, also fail to detect blood collection device problems $(7,8)$. 
Hence, QC and proficiency testing specimens in clinical laboratories are analyzed but not processed as patient specimens are. Although QC specimens are typically non-commutable with native patient specimens because the QC matrices are usually altered by manufacturing processes from that of native specimens, the comparison of control sera results from specimens exposed and nonexposed to BCTs could potentially reveal the adverse effects of additives $(7,8,93)$. This could be done by clinical laboratories or perhaps by tube manufacturers by exposing QC sera to BCTs on a lot-by-lot basis. When laboratorians change the tubes they use, they should also perform a comparative tube evaluation (94); this tube comparison study should be similar to the one described for method comparison studies, using the CLSI EP9-A guideline (95). In addition to contacting tube manufacturers, tube-related issues should also be reported to regulatory agencies (i.e., Food and Drug Administration) via MedWatch in the United States and the Medicines Healthcare Products Authority in the United Kingdom. Finally, the routine evaluation of BCTs by clinical laboratories should be incorporated into QC plans based on risk management to help prevent or detect tube-related errors and enhance the quality of the test results (96).

The BD Diagnostics preanalytical division has developed a program through an Instrument Company Liaison to work with assay manufacturers to identify and eliminate and/or reduce tube-related assay problems prior to products being commercialized $(97,98,99)$. A CLSI guideline is available for

\section{References}

1. Lillenfiled AM, Bross I, Sartwell PE. Observations on an outbreak of infectious hepatitis in Baltimore during 1951. Amer J Pub Health 1953;43:1085-96.

2. Funderburk JV. "System for lubricating a syringe barrel", U.S. Patent No. 5,456,940, October 1995.

3. MacNutt MJ, Sheel AW. Performance of evacuated blood collection tubes at high altitude. High Alt Med Bio 2008;9:235-7. http://dx.doi.org/10.1089/ham.2008.1027. tube manufacturers, in vitro diagnostic manufacturers, and clinical laboratories for verification and validation of venous and capillary BCTs for chemistry, immunochemistry, hematology, and coagulation $(99,100)$.

\section{Conclusions}

Although current BCTs largely work as designed and are therefore often taken for granted, it is important that laboratorians become aware of the potential problems that they can cause in the analysis of specimens. BCTs are medical devices and, as such, have inherent limitations. When improperly used or because of problems related to their manufacturing, BCT-related interferences in test results can adversely influence patient outcomes, decrease laboratory efficiency, delay test results, and increase the cost per test due to recollection and retesting. Thus, optimization and standardization of BCTs are vital for the reliable test analysis. Because laboratory test result quality ultimately depends on specimen integrity, tube manufacturers, in vitro diagnostic companies, and laboratorians should all remain vigilant in protecting against the adverse effects of BCT problems on clinical laboratory assays.

\section{Acknowledgements}

The authors would like to thank Ms. Krista Tanquary for editing and reviewing of the manuscript.

\section{Potential conflict of interest}

None declared.

4. Boeynaems JM, De Leener A, Dessars B, Villa-Lobos HR, Aubry JC, Cotton F, Thiry P. Evaluation of a new generation of plastic evacuated blood-collection tubes in clinical chemistry, therapeutic drug monitoring, hormone and trace metal analysis. Clin Chem Lab Med 2004;42:67-71. http:// dx.doi.org/10.1515/CCLM.2004.013.

5. Daves $M$, Trevisan $D$, Cemin R. Different collection tubes in cardiac biomarkers detection. J Clin Lab Anal 2008;22:391-4. http://dx.doi.org/10.1002/jcla.20277. 
6. Bush VJ, Leonard L, Szamosi DI. Advancements in blood coIlection devices. Lab Med 1998;29:616-22.

7. Bowen RAR, Chan Y, Cohen J, Rehak NN, Hortin GL, Csako $G$, et al. Effect of blood collection tubes on total triidothyronine and other laboratory assay. Clin Chem 2005;51:42433. http://dx.doi.org/10.1373/clinchem.2004.043349.

8. Bowen RAR, Chan Y, Ruddel ME, Hortin GL, Csako G, Demosky SJ, et al. Immunoassay interference by a commonly used blood collection tube additive, the organosilicone surfactant silwet L-720. Clin Chem 2005;51:1874-82. http:// dx.doi.org/10.1373/clinchem.2005.055400.

9. Vogler EA. "Blood collection assembly including mechanical phase separating insert", U.S. Patent No. 5,533,518, July 1996.

10. Dubrowny NE, Harrop AJ. "Collection device", U.S. Patent No. 6,686,204, February 2004.

11. Burns JA. "Blood microcollection tube assembly", U.S. Patent No. 5,288,466, February 1994.

12. Narayanan S, Lin FC. Sampling technique. In: Wong SHY, ed. Therapeutic drug monitoring and toxicology by liquid chromatography. New York: Marcel Dekker, Inc.; 1985. p. 79-88.

13. Hulon W. "Blood collection tube assembly", U.S. Patent No. 5,297,561, March 1994.

14. Gorbet M, Sefron M. Biomaterial-associated thrombosis: roles of coagulation factors, complement platelets and leukocytes. Biomaterials 2004;25:5681-703. http://dx.doi. org/10.1016/j.biomaterials.2004.01.023.

15. Ernst DJ. Plastic collection tubes decrease risk of employee injury. MLO Med Lab Obs 2001;33:44-6.

16. Vogler EA, Siedlecki CA. Contact activation of blood plasma coagulation: a contribution from the hematology at biomaterial interfaces research group the Pennsylvania State University. Biomaterials 2009;30:1857-69. http://dx.doi. org/10.1016/j.biomaterials.2008.12.041.

17. Anderson DR, Wiseman J, MacLeod J, Burton E, Zayed $E$. Evaluation of polyethylene terephthalate for $A B O$ and $R h$ typing and alloantibody screening. Transfusion 2000;40:669-72. http://dx.doi.org/10.1046/j.1537-2995. 2000.40060669.x.

18. Kratz A. A comparison of glass and plastic blood collection tubes for routine and specialized coagulation assays: $A$ comprehensive study. Arch Pathol Lab Med 2006;130:39-44.

19. Smets EM, Dijkstra-Lagemaat JE, Blankenstein MA. Influence of blood collection in plastic vs. glass evacuated serum-separator tubes on hormone and tumour marker levels. Clin Chem Lab Med 2004;42:435-9. http://dx.doi. org/10.1515/CCLM.2004.076.

20. Landry ML, Garner R, Ferguson D. Use of plastic Vacutainer tubes for quantification of human immunodeficiency virus type I in blood specimens. J Clin Microbiol 2001;39:354-6. http://dx.doi.org/10.1128/JCM.39.1.354-356.2001.

21. Feng CS, Wan CP. The plastic tube compared with the glass tube in blood bank tests. Pathol 1988;20:309-10. http:// dx.doi.org/10.3109/00313028809059518.

22. Flanders MM, Crist $R$, Rodgers GM. A comparison of blood collection in glass versus plastic Vacutainers on results of esoteric coagulation assays. Lab Med 2003;34:732-5. http://dx.doi.org/10.1309/BMQHCD6B8984RLA3.
23. Anraku H, Shoji Y. "Vacuum blood collection tubes", U.S. Pa tent No. 8,565,334, August 1989.

24. Montgomery $D B$, Vogler EA. "Tube having regions of different surface chemistry and method therefore", U.S. Patent No. 5,318,806, June 1994.

25. Percarpio EP, Holderith WJ, Wyckoff. "Vacuum indicator closure for a blood collection tube", U.S. Patent No. 4,293,078, November 1979.

26. Wang $\mathrm{H}-\mathrm{C}$, Wong WK. "Cured rubber components for use with pharmaceutical devices", U.S. Patent No. 7,282,269, December 2002.

27. Shah VP, Knapp G, Skelly JP, Cabana BE. Interference with measurements of certain drugs in plasma by a plasticizer in Vacutainer tubes. Clin Chem 1982;28:2327.

28. Borga O, Piafsky KM, Nilsen OG. Plasma protein binding of basic drugs. I. Selective displacement from a1-acid glycoprotein by tris (2-butoxyethyl) phosphate. Clin Pharmacol Ther 1977;22:539-44.

29. Cotham RH, Shand D. Spuriously low plasma propranolol concentrations resulting from blood collection methods. Clin Pharmacol Ther 1975;18:535-8.

30. Janknegt R, Lohman JJ, Hooymans PM, Merkus FW. Do evacuated blood collection tubes interfere with therapeutic drug monitoring? Pharm Weekbl Sci Ed 1983;5:287-90.

31. Curry W, Conway S, Goodfield C, Miller K, Mueller RL, Polini E. Reducing the risk of contamination of Sterile Parenteral products via closure components. AAPS PharmSciTech 2010;11:1572-9. http://dx.doi.org/10.1208/s12249-010 9531-8.

32. Van den Besselaar AMHP, Van Dam W, Sturk A, Bertina RM Prothrombin time ratio is reduced by magnesium contamination in evacuated BCTs. Thromb Haemost 2001;85:647-50.

33. Cummings J. Evacuated tubes for monitoring heparin treatment. Thromb Haemost 1981;34:939-40.

34. Cohen RR. "Evacuated sample collection tube with aqueous additive", U.S. patent No 5,860,937, January 1999.

35. Chowdry FR, Rodman H, Bleicher SJ. Glycerol-like contamination of commercial blood sampling tubes. J Lipid Res 1971;12:116.

36. DrakeSK, Bowen RAR, Remaley AT, Hortin GL. Potential interferences from blood collection tubes in mass spectrometric analyses of serum polypeptides. Clin Chem 2004;50:2398401. http://dx.doi.org/10.1373/clinchem.2004.040303.

37. Ladenson JH, Tsai LMB, Michael JM. Serum versus heparinized plasma for eighteen common chemistry tests. Am J Clin Pathol 1974;62:545-52.

38. Sevastos N, Theodossiades G, Efstathiou S, Papatheodoridis GV, Manesis E, Archimandritis AJ. Pseudohyperkalemia in serum: the phenomenon and its clinical magnitude. $J$ Lab Clin Med 2006;147:139-44. http://dx.doi.org/10.1016/j. lab.2005.11.008.

39. Assembly and method to improve vacuum retention in evacuated specimen containers. Available at www. freshpatents. com/dt20090625ptan200901625.php. Accessed April 2013.

40. Clinical and Laboratory Standards Institute (CLSI): Procedures for the Collection of Diagnostic Blood Specimens by Venipuncture; Approved Standard - Fourth Edition. CLSI document H3-A4. Wayne, PA: Clinical and Laboratory Standards Institute; 2005. 
41. Young DS, Bermes EW, Haverstick DM. Specimen collection and processing. In: Burtis CA, Ashwood ER, Bruns DE, eds. Tietz Textbook of Clinical Chemistry and Molecular Diagnostics. 4th Ed. St. Louis: Elsevier Saunders; 2006.

42. Becton Dickinson website. Available at: www.bd.com. Accessed May 2013.

43. Tate J, Ward G. Interferences in immunoassay. Clin Biochem 2004;25:105-20.

44. Cuhadar S. Preanalytical variables and factors that interfere with the biochemical parameters: a review. OA Biotechnology 2013;2:19.

45. Toffaletti JR, Wildermann RF. The effects of heparin anticoagulants and fill volume in blood gas syringes on ionized calcium and magnesium measurements. Clin Chem Acta 2001;304:147-51. http://dx.doi.org/10.1016/S0009-8981(00)00412-5.

46. Zaninotto M. Quality specifications for biochemical markers of myocardial injury. Clin Chim Acta 2004;346:65-72. http://dx.doi.org/10.1016/j.cccn.2004.02.035.

47. Wild D, John $R$, Sheehan C, eds. The Immunoassay Handbook. 4th ed. Oxford, UK: Elsevier; 2013.

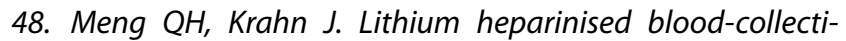
on tubes give falsely low albumin results with an automated bromcresol green method in haemodialysis patients. Clin Chem Lab Med 2008;46:396-400. http://dx.doi. org/10.1515/CCLM.2008.079.

49. Tammen $H$, Schulte I, Hess $R$, Menzel C, Kellmann M, Mohring $T$, et al. Peptidomic analysis of human blood specimens: comparison between plasma specimens and serum by differential peptide display. Proteomics 2005;13:341422. http://dx.doi.org/10.1002/pmic.200401219.

50. Lippi G, Avanzini P, Cosmai M, Aloe R, Ernst D. Incomplete filling of lithium heparin tubes affects the activity of creatine kinase and gamma-utamyltransferase. Br J Biomed Sci 2012;69:67-70.

51. Narayanan S. The preanalytic phase: an important component of laboratory medicine. Am J Clin Pathol 2000;1 13:42952. http://dx.doi.org/10.1309/CONM-Q7RO-LL2E-B3UY.

52. Li G, Cabanero M, Wang $Z$, Wang $H$, Huang $T$, Alexis $H$, et al. Comparison of glucose determinations on blood samples collected in three types of tubes. Ann Clin Lab Sci 2013;43:278-84.

53. Peake MJ, Bruns DE, Sacks DB, Horvath AR. It's time for a better blood collection tube to improve the reliability of glucose results. Diabetes Care 2013;36:e2. http://dx.doi. org/10.2337/dc12-1312.

54. Gambino R. Sodium fluoride: an ineffective inhibitor of glycolysis. Ann Clin Biochem 2013; 50:3-5. http://dx.doi. org/10.1258/acb.2012.012135.

55. Gigliello JF, Kragle HA. "Method and apparatus for multiphase fluid collection and separation", U.S. Patent No. 3,920,549, November 1975.

56. Bush VJ, Janu MR, Bathur F, Wells A, Dasgupta A. Comparison of BD Vacutainer SST plus tubes and BD SST II plus tubes for common analytes. Clin Chem 2001;306:139-43.

57. Spiritus T, Zaman Z, Desmet W. lodinated contrast media interfere with gel barrier formation in plasma and serum separator tubes. Clin Chem 2003;49:1187-9. http://dx.doi. org/10.1373/49.7.1187.
58. Fatas $M$, Franquelo P, Franquelo R. Anomalous flotation of separatorgel:density or viscosity? Clin Chem 2008;54:771-2. http://dx.doi.org/10.1373/clinchem.2007.093716.

59. Faught RC, Marshall J, Bornhorst J. Solution densities and estimated total protein contents associated with inappropriate floatation of separator gel in different blood collection tubes. Arch Pathol Lab Med 2011;135:1081-4. http:// dx.doi.org/10.5858/2010-0488-OAR.1.

60. Bergqvist $Y$, Eckerbom $S$, Funding $L$. Effect of use of gelbarrier sampling tubes on determination of some antiepileptic drugs in serum. Clin Chem 1984;30:465-6.

61. Koch TR, Platoff G. Suitability of collection tubes with separator gels for therapeutic drug monitoring. Ther Drug Monit 1990;12:277-80. http://dx.doi.org/10.1097/00007691199005000-00011.

62. Chance J. Evaluation of the BD Vacutainer ${ }^{\oplus}$ SST ${ }^{\text {TM }}$ // blood collection tube for special chemistry analytes. Clin Chem Lab Med 2009;47:358-61. http://dx.doi.org/10.1515/ CCLM.2009.072.

63. Babic N, Zibrat S, Gordon IO, Lee CC, Yeo KT. Effect of blood collection tubes on the incidence of artifactual hyperkalemia on patient samples from an outreach clinic. Clin Chim Acta 2012;413:1454-8. http://dx.doi.org/10.1016/j. cca.2012.06.001.

64. Ji SQ, Evenson MA. Effects of contaminants in blood-collection devices on measurement of therapeutic drugs. Clin Chem 1983;29:456-61.

65. Shi RZ, van Rossum $H H$, Bowen RA. Serum testosterone quantitation by liquid chromatography-tandem mass spectrometry: Interference from blood collection tubes. Clin Biochem 2012;45:1706-9. http://dx.doi.org/10.1016/j. clinbiochem.2012.08.008.

66. Dimeski G, Masci PP, Trabi M, Lavin MF, de Jersey J. Evaluation of the Becton-Dickinson rapid serum tube: does it provide a suitable alternative to lithium heparin plasma tubes? Clin Chem Lab Med 2010;48:651-7. http://dx.doi. org/10.1515/CCLM.2010.141.

67. Ng WY, Yeo CP. Thrombin-accelerated quick clotting serum tubes: an evaluation with 22 common biochemical analytes. Adv Hematol 2013; In press. http://dx.doi. org/10.1155/2013/769479.

68. Sampson $M$, Ruddel $M$, Albright S, Elin RJ. Positive interference in lithium determinations from clot activator in COllection container. Clin Chem 1997;43:675-9.

69. Wang C, Shiraishi S, Leung A, Baravarian S, Hull L, Goh V, et al. Validation of a testosterone and dihydrotestosterone liquid chromatography tandem mass spectrometry assay: interference and comparison with established methods. Steroids 2008;73:1345-52. http://dx.doi.org/10.1016/j. steroids.2008.05.004.

70. Pilny R, Bouchal P, Borilova S, Ceskova P, Zaloudik J, Vyzula $R$, et al. Surface-enhanced laser desorption ionization/ time-of-flight mass spectrometry reveals significant artifacts in serum obtained from clot activator-containing coIlection devices. Clin Chem 2006;52:2115-6. http://dx.doi. org/10.1373/clinchem.2006.073841.

71. Mannello F. Serum or plasma samples? The "Cinderella" role of blood collection procedures preanalytical methodological issues influence the release and activity of circulating matrix metalloproteinases and their tissue inhibitors, hampering diagnostic trueness and leading to misinterpretation. Arterioscler Thromb Vasc Biol 2008;28:611-14. http://dx.doi.org/10.1161/ATVBAHA.107.159608. 
72. Brady AM, Spencer BL, Falsey AR, Nahm MH. Blood collection tubes influence serum ficolin-1 and ficolin-2 levels. Clin Vaccine Immunol 2013; in press.

73. Gadow A, Fricke H, Strasburger CJ, Wood WG. Synthesis and evaluation of luminescent tracers and hapten-protein conjugates for use in luminescence immunoassays with immobilized antibodies and antigens. A critical study of macro solid phases for use in immunoassay systems, part II. J Clin Chem Clin Biochem 1984;22:337-47.

74. Wickus GG, Mordan RJ, Mathews EA. Interference in the Allegro immunoassay system when blood is collected in silicone-coated tubes [letter]. Clin Chem 1992;38:2347-8.

75. Vogler EA, Shepard TA, Graper JC. "Blood compatible, shear sensitive gels" European. Patent No.0678557, June 2000.

76. Wang S, Ho V, Roquemore-Goins A, Smith FA. Effects of blood collection tubes including pediatric devices, on 16 common immunoassays. Clin Chem 2006;52:892-3. http:// dx.doi.org/10.1373/clinchem.2006.068361.

77. McKiel RR, Barron N, Needham CJ, Wilkins TA. Siliconized vs. nonsiliconized evacuated blood-collection tubes for free thyroxin measurements. Clin Chem 1982;28:2333.

78. Yin P, Peter A, Franken $H$, Zhao X, Neukamm SS, Rosenbaum $L$, et al. Preanalytical aspects and sample quality assessment in metabolomics studies of human blood. Clin Chem 2013;25:833-45. http://dx.doi.org/10.1373/ clinchem.2012.199257.

79. Bowen RAR, Vu C, Remaley AT, Hortin GL, Csako G. Differential effect of blood collection tubes on total free fatty acids (FFA) and total triiodothyronine (TT3) concentration: a model for studying interference from tube constituents. Clin Chim Acta 2007;378:181-93. http://dx.doi.org/10.1016/j. cca.2006.11.020.

80. Calam R, Cooper M. Recommended "order of draw" for collecting blood specimens into additive-containing tubes. Clin Chem 1982;28:1399.

81. Clinical and Laboratory Standards Institute (CLSI): Procedure for the Collection of Diagnostic Blood Specimens by Venipuncture. Approved Standard - Fifth Edition. CLSI document H3-A5. Wayne, PA: Clinical and Laboratory Standards Institute; 2007.

82. Salvagno G, Lima-Oliveira G, Brocco G, Danese E, Guidi GC, Lippi G. The order of draw: myth or science? Clin Chem Lab Med 2013;12:1-5.

83. Hortin GL, Sviridov D, Anderson NL. High-abundance polypeptides of the human plasma proteome comprising the top 4 logs of polypeptide abundance. Clin Chem 2008;54:1608-16. http://dx.doi.org/10.1373/ clinchem.2008.108175.

84. Menssen HD, Brandt $N$, Leben $R$, Muller F, Thiel E, Melber $K$. Measurement of hematological, clinical chemistry, and infection parameters from hirudinized blood collected in universal blood sampling tubes. Semin Thromb Hemost 2001;27:349-56. http://dx.doi.org/10.1055/s-2001-16888.

85. Joly D, Drueke TB, Alberti C, Houillier P, Lawson-Body E, Martin KJ, et al. Variation in serum and plasma PTH levels in second-generation assays in hemodialysis patients: cross-sectional study. Am J Kidney Dis 2008;51:987-95. http:// dx.doi.org/10.1053/j.ajkd.2008.01.017.
86. Evans MJ, Livesey JH, Ellis MJ, Yandle TG. Effect of anticoagulants and storage temperatures on stability of plasma and serum hormones. Clin Biochem 2001;34:107-12. http://dx.doi.org/10.1016/S0009-9120(01)00196-5.

87. Kim W, Egan JM. The role of incretins in glucose homeostasis and diabetes treatment. Pharmacol Rev 2008;60:470512. http://dx.doi.org/10.1124/pr.108.000604.

88. Rai AJ, Gelfand CA, Haywood BC, Warunek DJ, Yi J, Schuchard MD, et al. HUPO Plasma Proteome Project specimen collection and handling: towards the standardization of parameters for plasma proteome samples. Proteomics 2005;5:3262-77. http://dx.doi.org/10.1002/pmic.200401245.

89. Nilsson TK, Boman K, Jansson JH, Thogersen AM, Berggren $M$, Broberg $A$, et al. Comparison of soluble thrombomodulin, von Willebrand factor, tPA/PAl-1 complex, and high-sensitivity CRP concentrations in serum, EDTA plasma, citrated plasma, and acidified citrated plasma (Stabilyte) stored at -70 degrees C for 8-11 years. Thromb Res 2005;116:249-54. http://dx.doi.org/10.1016/j.thromres.2004.12.005.

90. Hortin GL, Warshawsky I, Laude-Sharp M. Macromolecular chromogenic substrates for measuring proteinase activity. Clin Chem 2001;47:215-22.

91. Sapin R, Ongagna JC, Gasser F, Grucker D. Insulin measurements in haemolysed serum: influence of insulinase inhibitors. Clin Chim Acta 1998;274:111-17. http://dx.doi. org/10.1016/S0009-8981(98)00051-5.

92. Ayache S, Panelli M, Marincola FM, Stroncek DF. Effects of storage time and exogenous protease inhibitors on plasma protein levels. Am J Clin Pathol 2006;126:174-84. http://dx.doi.org/10.1309/3WM7XJ7RD8BCLNKX.

93. Bowen RA, Sattayapiwat A, Gounden V, Remaley AT. Blood collection tube-related alterations in analyte concentrations in quality control material and serum specimens. Clin Biochem 2013; in press. http://dx.doi.org/10.1016/j. clinbiochem.2013.11.003.

94. Lima-Oliveira G, Lippi G, Salvagno GL, Montagnana M, Picheth $G$, Guidi GC. Preanalytical management: serum vacuum tubes validation for routine clinical chemistry. Biochem Med 2012;22:180-6. http://dx.doi.org/10.11613/BM.2012.021.

95. Clinical and Laboratory Standards Institute (CLSI): Method Comparison and Bias Estimation Using Patient Samples; Approved Guideline. CLSI document EP9-A. Wayne, PA: Clinical and Laboratory Standards Institute; 1992.

96. Nichols JH. Laboratory quality control based on risk management. Ann Saudi Med 2011;31:223-28. http://dx.doi. org/10.4103/0256-4947.81526.

97. Stankovic AK, Silvestri J, Mails $M$, Najork C. Total quality in laboratory diagnostics: the role of commercial companies. Biochem Med 2010; 20: 207-14. http://dx.doi. org/10.11613/BM.2010.025.

98. Parham S. Test tube interference shows 'chink in armor.' CAP Today 2005; 19:68-72.

99. Bowen RAR, Hortin GL, Csako G, Otanez O, Remaley AT. Impact of blood collection devices on clinical chemistry assays. Clin Biochem 2010;43:4-25. http://dx.doi. org/10.1016/j.clinbiochem.2009.10.001.

100. Clinical and Laboratory Standards Institute (CLSI): Validation and Verification of Tubes for Venous and Capillary Blood Specimen Collection; Approved Guideline. CLSI document GP34-A. Wayne, PA: Clinical and Laboratory Standards Institute; 2010. 